\title{
Modeling Biomass Procurement Tradeoffs within a Cellulosic Biofuel Cost Model
}

\begin{abstract}
We develop a long-run cellulosic biofuel cost model that minimizes feedstock procurement and processing costs per gallon. The distinguishing feature of the model is that it accounts for the procurement tradeoff between the intensive margin (biomass producers' participation rate) and extensive margin (biomass capture region). To investigate the extent to which this procurement trade-off affects processors' cost-minimizing decisions, we apply the model to switchgrass ethanol production in U.S. crop reporting districts. Results suggest that location characteristics will determine the extent to which processors can reduce their total procurement costs by offering a higher biomass price to increase participation near the plant and reduce transportation costs.
\end{abstract}

\section{Key Words}

biofuel, biomass, cellulosic ethanol, procurement, RFS2, switchgrass

JEL Codes

Q16, Q42, Q41, Q11

(C) 2016. This manuscript version is made available under the Elsevier user license http://www.elsevier.com/open-access/userlicense/1.0/ 


\section{Introduction}

Unstable energy prices and energy security, as well as environmental impacts of fossil fuels, have increased global interest in alternative and renewable energy sources. One potential energy source is cellulosic biofuel. By using feedstock such as grasses and crop residues, cellulosic biofuel is a renewable substitute for traditional transportation fuels. Several countries have implemented policies to encourage cellulosic biofuel development (An et al. 2011), but the economics of cellulosic biofuel production have limited industry expansion. U.S. cellulosic biofuel production has been well below initial policy targets. ${ }^{1}$

It is generally agreed that significant cellulosic biofuel expansion will require more certainty in future cellulosic biofuel demand or improved efficiencies and lower costs in both feedstock procurement and biofuel processing (Miranowski et al. 2010; Sharma et al. 2013). As the industry is moving from pilot- to commercial-scale operations and policymakers are considering future biofuel policy, it is an opportune time to look more closely at commercial-scale cellulosic biofuel processor decisions as well as potential tradeoffs within these decisions.

A major challenge for cellulosic biofuel producers is identifying the optimum plant size given expected local supply of feedstock; processors must weigh processing cost economies of a larger plant with cost diseconomies of feedstock procurement. A plant built to a specific capacity based on expected local feedstock supply may find importing feedstock from outside the local market prohibitively expensive if local shortfalls occur. ${ }^{2}$

\footnotetext{
${ }^{1}$ The U.S. Revised Renewable Fuels Standard (RFS2) outlined in the 2007 Energy Independence and Security Act (EISA) includes a cellulosic biofuel volume requirement that increases from 100 million gallons in 2010 to 16 billion gallons in 2022 (U.S. EPA 2012). Actual U.S. cellulosic biofuel production has not expanded as rapidly as the mandated quantities.

${ }^{2}$ This differs from traditional commodity crops such as corn, soybeans, small grains, etc. Established infrastructure for production, storage, and transportation allows commoditized crops to be traded on regional, national, and global markets. While commodity-based biofuel plants may get a majority of their feedstock from the local region, additional feedstock can be imported from another region without incurring prohibitively higher short-run feedstock costs. Infrastructure of this type has not yet developed for biomass (Babcock et al. 2011, Miranowski et al. 2010).
} 
We present a long-run cost model that identifies the optimal combination of plant size and feedstock procurement to minimize biofuel costs per gallon for a given location. The common approach in the literature is to assume there is a fixed amount of local land allocated to biomass production. Any increase in feedstock demand is met by purchasing biomass from more distant areas in the local market (e.g., Brechbill and Tyner 2008, Gan and Smith 2011, Haque and Epplin 2012, Khanna et al. 2011, Leboreiro and Hilaly 2011, Parker et al. 2011, Popp and Hogan Jr. 2007, Rosburg and Miranowski 2011, U.S. DOE 2011). The model proposed here relaxes this assumption by making the biomass price offered by the processor a choice variable. Increases in local biomass supply may be achieved by increasing the price paid for delivered feedstock, thus increasing biomass production (participation) nearer the plant as well as beyond. We explore how participation rate and capture distance affect the processor's cost-minimizing decision and the potential local feedstock supply. ${ }^{3}$

This article presents a descriptive overview of the model, with a detailed description of the model available in the online supplementary appendix. The model is operationalized using switchgrass as a feedstock for ethanol production and assumptions regarding biofuel processing costs, switchgrass production costs, feedstock transportation costs, and the opportunity cost of potential biomass cropland. Non-linear optimization is used to find expected cost-minimizing combinations of biomass price and plant size for each location. Then we identify location characteristics that jointly determine plant size and biofuel production.

\footnotetext{
${ }^{3}$ To our knowledge, the cost model we present is the first to account for this procurement trade-off. A working paper version of this model was initially presented online in Rosburg et al. (2012) and Rosburg (2012). While Leboreiro and Hilaly (2011) acknowledge the existence of this tradeoff, their analysis uses a fixed participation rate. More recently, Sesmero and Gramig (2013) and Sesmero et al. (2014) consider the intensive and extensive margin trade-off for stover procurement in Indiana, and Yu et al. (2014) include an intensive and extensive trade-off for a switchgrass supply system in Tennessee.
} 


\section{Cellulosic biofuel cost model}

We model a biofuel processor who considers building a commercial-scale biofuel plant at a given location. The processor's objective is to minimize the long-run total cost per gallon. ${ }^{4}$ This objective is achieved by choosing the optimal plant size subject to the cost of procuring feedstock delivered to the plant.

The processor's cost function has two components: biomass conversion costs and biomass procurement costs. Biomass conversion costs include operating and capital costs; operating costs are assumed independent of plant size while capital costs are assumed to exhibit economies of plant size (Brown 2003). Biomass procurement costs include the cost to acquire, store, and deliver feedstock to the plant.

In this model, the local supply of biomass depends on the price offered, and the processor pays each biomass supplier the same price per ton of delivered feedstock. Biomass producers have different land opportunity costs and may respond differently to market prices. As biomass price increases, producers within the capture radius of the plant may choose to supply biomass in greater quantities. We refer to this as the local participation rate function and it is non-decreasing in the biomass price. Modeling the participation rate as a function of price is a departure from models that assume a fixed local participation rate, where the processor takes the local field-side biomass price as given and increases in biomass demand (i.e., increase in plant size) are met by increasing the radius of the local biomass supply area. ${ }^{5}$ Recent farmer surveys provide evidence that farmers in many regions are willing to allocate more land to biomass production as the

\footnotetext{
${ }^{4}$ Optimal biofuel plant size is determined by minimizing long-run average cost rather than maximizing long-run profits. Given current conditions, cellulosic biofuel is not likely to achieve long-run breakeven, implying a plant size of zero without significant fiscal incentives, higher fuel prices, or enforced mandates (Rosburg and Miranowski 2011).

${ }^{5}$ Recent examples include: Gan and Smith (2011), Haque and Epplin (2012), Leboreiro and Hilaly (2011), and Parker et al. (2011).
} 
biomass price increases. Further, farmers may differ in the minimum price at which they are willing to supply biomass even under relatively uniform production conditions (Altman et al. 2015; Bergtold et al. 2014, Menard et al. 2011, Qualls et al. 2011). Modeling participation as a function of biomass price allows processors to increase feedstock supply closer to the plant by increasing the offer price.

With a variable participation rate, the optimal biomass price (or intersection of biomass derived demand and local biomass supply) will occur where the marginal benefits from increasing plant size are equal to the marginal costs of acquiring additional feedstock for each location. Figure 1 illustrates how this model compares with biofuel cost models that fix the participation rate.

Figure 1 - Biofuel cost function for a select location

(a) Fixed participation rate

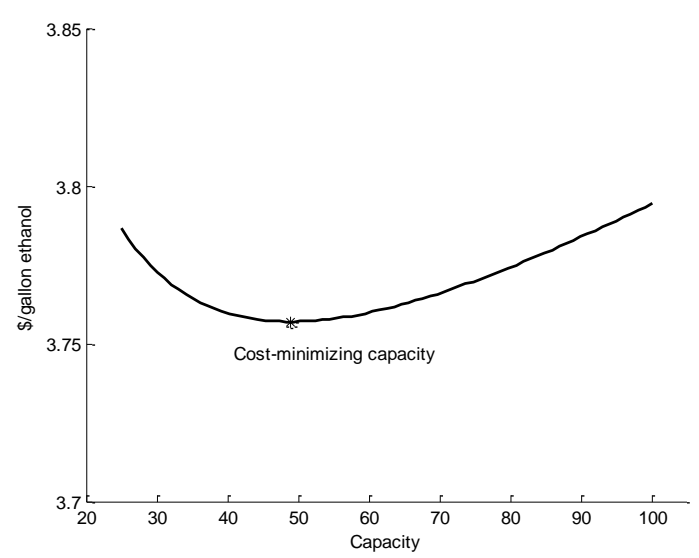

(b). Participation rate function

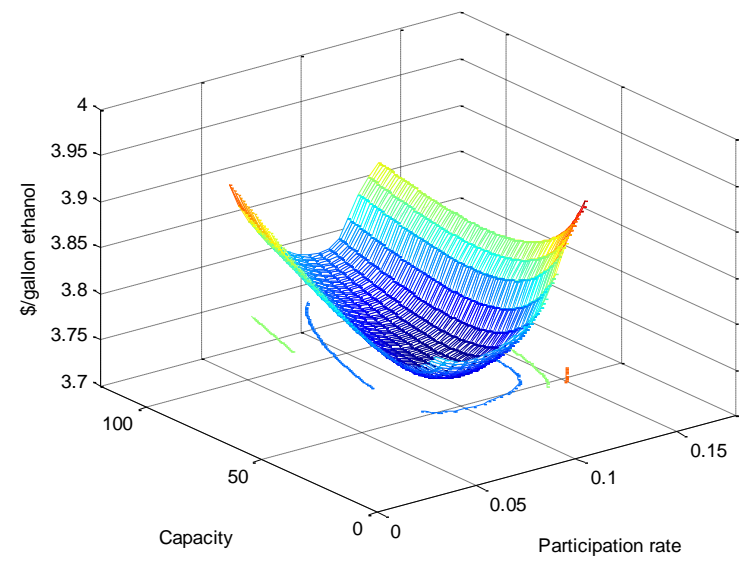

In models where the participation rate is fixed, there is a single cost-minimizing plant size choice, as in Figure 1(a). The model proposed here identifies the least cost combination of plant size and participation rate (i.e., minimum point on the cost surface). Allowing participation rates to vary reveals the set of isocost lines that form the cost surface depicted in Figure 1(b). The extent to which biofuel cost and plant size are over- or underestimated using the approach in 
Figure 1(a) will depend on how close the fixed participation rate and biomass price are to the values at the minimum point in Figure 1(b).

\section{Data and empirical approach}

The cost model is applied to switchgrass production in the United States. Potential processing plant locations are defined as U.S. crop reporting districts (CRDs) for rain-fed regions where production data are available. ${ }^{6}$ The analysis is based on production data from 182 CRDs. The model limits each district to one plant to avoid double-counting acreage and overestimating potential biofuel supply. ${ }^{7}$

Biofuel processing costs are based on engineering cost estimates for a biomass to ethanol plant using a biochemical process (Kazi et al. 2010). ${ }^{8}$ Biochemical processing is the technology used in three U.S. commercial cellulosic biofuel plants under development, and engineering cost estimates are documented in Aden (2008, 2009), Aden et al. (2002), and Kazi et al. (2010). A detailed summary of the data, including specific parameter values, can be found in the supplementary online appendix (Table A.1).

Switchgrass is a dedicated energy crop whose production on a commercial scale is relatively new. It is generally thought that switchgrass will compete with other low opportunity cost crops (English et al. 2006; Yu et al. 2014). Following the existing literature, we limit the acreage available for switchgrass production in each district to $10 \%$ of harvested cropland and $25 \%$ of

\footnotetext{
${ }^{6}$ County-level land area was frequently insufficient to supply enough biomass for a commercial-scale plant. Rainfed regions include the Northern and Southern Plains, Corn Belt, Lake States, Delta States, Southeast, Appalachia, and Northeast. Four districts located in south and east Texas were removed because of low switchgrass yields and high switchgrass production costs.

${ }^{7}$ Sensitivity analysis on the one biorefinery restriction was conducted. A second biorefinery is generally not economically feasible unless biomass procurement and biofuel processing costs are significantly reduced (results available in Rosburg 2012).

${ }^{8}$ The plant outlined in Kazi et al. (2010) is for corn stover to ethanol. We assume conversion costs are similar for switchgrass to ethanol and equal for all locations.
} 
cropland pasture, permanent pasture, failed cropland, and CRP acreage. ${ }^{9}$ The percentage of available acreage that will be used to supply biomass is determined by the local participation rate, which depends on the price offered by the plant. A farmer will participate in supplying biomass if the offered price exceeds his opportunity cost. All farmers in each district are assigned the CRD average switchgrass production costs and average yield; however, land opportunity costs per acre are allowed to vary within the district, as discussed shortly. The basis for this assumption is that switchgrass yields on marginal cropland exhibit less variance with soil quality than traditional (cash) crops. ${ }^{10}$

Switchgrass yields for each district are $75 \%$ of the simulated yield values from the crop productivity model MISCANMOD (Khanna et al. 2011). The lower yield assumption reflects recent field and adjusted plot trials and accounts for lower collection efficiency and additional handling losses (Rosburg and Miranowski 2011). Switchgrass yields range from $1.4-6$ tons per acre with an average 4.2 tons per acre across all districts. ${ }^{11}$ Annualized establishment and harvest costs per ton for each district are also from Khanna et al. (2011) and adjusted to reflect the lower per acre yield assumption. Establishment and harvest costs average $\$ 50$ per ton across all districts and range from $\$ 38-\$ 76$ per ton $(2007 \$)$.

While farmers' non-land costs of switchgrass production and switchgrass yields are assumed equal for all farmers in a district, farmers' land opportunity costs vary. We proxy farmers' land opportunity costs within districts using actual offers from producers to enroll their land in the

\footnotetext{
${ }^{9}$ Acreage assumptions are similar to those made in de la Torre Ugarte et al. (2003), English et al. (2006), English et al. (2010), Khanna et al. (2011), Parker et al. (2011), and U.S. DOE (2011). Rosburg et al. (2012) report sensitivity of model results to the available acreage assumption.

10 The assumption of fixed switchgrass production costs and yields within districts underestimates the true variation in switchgrass production conditions. While switchgrass production costs and yields may be less dependent on soil quality than traditional crops, variation due to soil quality differences will still occur within districts. However, the data needed to identify variation in switchgrass production costs and yields within districts is not readily available.

${ }^{11}$ All ton values are on a dry weight basis (i.e., 2000 pounds dry matter).
} 
Conservation Reserve Program (CRP). The distribution of opportunity costs within a district is constructed based on parcel-specific productivity measures for land when switching from an annual to perennial production system. These distributions, switchgrass yields and production cost data are combined to estimate participation rate functions for each district. Using CRP data in this way makes it possible to incorporate land opportunity cost variations within a district that are otherwise difficult to proxy. ${ }^{12}$ While the CRP data are used to express the distribution of land opportunity costs within each district, they do not serve to limit the acreage considered in the analysis to CRP land. Rather, total switchgrass acreage is based on the participation rate function together with the maximum available acreage in each district (i.e., limited amounts of CRP acreage, cropland pasture, permanent pasture, failed cropland, and harvested cropland). ${ }^{13}$

\section{Results}

The cost-minimizing plant size and biomass supply for each of the 182 districts is estimated using non-linear optimization. These cost-minimizing combinations define optimal participation rates, capture radii, and biofuel supply costs. Summary statistics are provided in Table 1, and they indicate considerable variation in the cost-minimizing combinations across districts. ${ }^{14}$ The optimal plant sizes range from 10 to 117 million gallons per year (mgy), capture radii from 22 to 51 miles, and estimated opportunity costs range from $\$ 4$ to $\$ 58$ per dry ton. ${ }^{15}$

\footnotetext{
${ }^{12}$ We thank an anonymous referee for correctly point out that, as with perennial crop production, land opportunity costs in the CRP also include a foregone options value. This is discussed further in the online appendix.

${ }^{13}$ The supplemental online appendix provides further details on the CRP offers data used and the empirical estimation of the participation rate functions.

${ }^{14}$ Additional tables summarizing the cost-minimizing decisions, land availability, and offers data are provided in the supplementary online appendix.

${ }^{15}$ The reported ethanol cost range of $\$ 3.19$ to $\$ 4.57$ per gallon ethanol is equivalent to $\$ 4.80$ to $\$ 6.85$ per gallon gasoline equivalent.
} 
Table 1 - Summary statistics of cost-minimizing decisions across 182 districts

\begin{tabular}{|l|c|c|c|c|}
\hline & Plant size & $\begin{array}{c}\text { Capture } \\
\text { radius }\end{array}$ & $\begin{array}{c}\text { Opportunity } \\
\text { cost payment }\end{array}$ & Biofuel cost \\
\hline & $\mathbf{( m g y )}$ & $\mathbf{( m i l e s )}$ & $\mathbf{( \$ / d t )}$ & (\$/gallon ethanol) \\
\hline Average & 52 & 35 & 18.6 & 3.73 \\
\hline Median & 46 & 35 & 15 & 3.67 \\
\hline Range & $10-117$ & $22-51$ & $4-58$ & $3.19-4.57$ \\
\hline
\end{tabular}

The innovation of this cost model is that it captures the biomass procurement tradeoff between biomass supply expansion along the intensive and extensive margins (i.e., participation rate vs. capture radius). The relevant question then is, how does this trade-off matter in terms of the efficient expansion of biofuel supply? We address this question in two ways. First, we evaluate how the procurement tradeoff differs across the 182 districts. Second, we evaluate the impact on biofuel supply from our cost model relative to a model that does not account for this procurement tradeoff.

\subsection{District-level procurement tradeoffs}

The summary statistics in Table 1 provide insight into the spatial variation in procurement costs and plant sizes, but they do not provide a picture of the underlying economic trade-offs. Figure 2 illustrates the least-cost biofuel supplies at the district levels.

Figure 2. Estimated district-level switchgrass-ethanol supplies

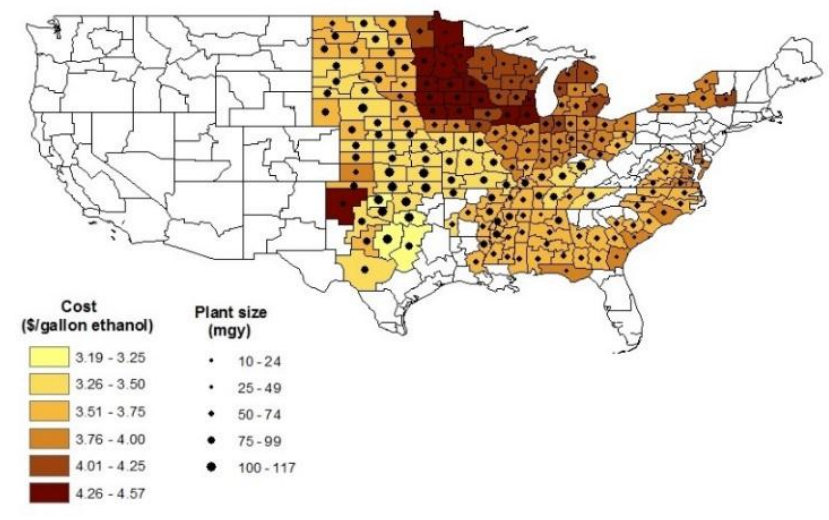


The degree to which a processor can capture cost savings and exploit plant size-procurement tradeoff varies greatly across districts. Given the parameters and assumptions used, switchgrass ethanol is, not surprisingly, less costly in rain-fed portions of northern Texas, Oklahoma, and southern Kansas ${ }^{16}$ because of relatively higher expected switchgrass yields, lower opportunity costs, and greater land availability for switchgrass production. Lower land opportunity costs mean biomass procurement at these locations is relatively low cost, characterized by high participation rates and a relatively small capture radius. As production expands to districts with lower switchgrass yields, higher opportunity cost land, and less available land, processors build smaller plants. In these districts, the optimal decision is to operate at a lower point along the local participation rate function and procure biomass from a larger radius. Figure 3 illustrates these trends in the procurement strategy; capture radius and participation rate for each plant are plotted against the plant's ethanol cost. For example, the first dot and first circle - the lowestcost plant as measured by ethanol costs ( $\$ 3.19$ per gallon) - has a capture radius of 29 miles and participation rate of $99 \%$, respectively. ${ }^{17}$ As biomass production expands, the optimal biomass procurement strategy shifts from a smaller capture radius and higher participation rate (intensive margin) to a larger capture radius and lower participation rate (extensive margin).

\footnotetext{
${ }^{16}$ Switchgrass production requires limited water relative to traditional cash crops (e.g., corn), which is one reason switchgrass was selected as the model herbaceous energy crop for biofuel feedstock (U.S. DOE 2011, Wright and Turhollow 2010).

${ }^{17}$ Recall that the participation rate reflects the percentage of "available land" that supplies biomass. Available land includes limited amounts of CRP acreage, cropland pasture, permanent pasture, failed cropland, and harvested cropland in each district (see the supplementary online appendix for complete assumptions).
} 
Figure 3 - Cost-minimizing procurement decisions as supply increases

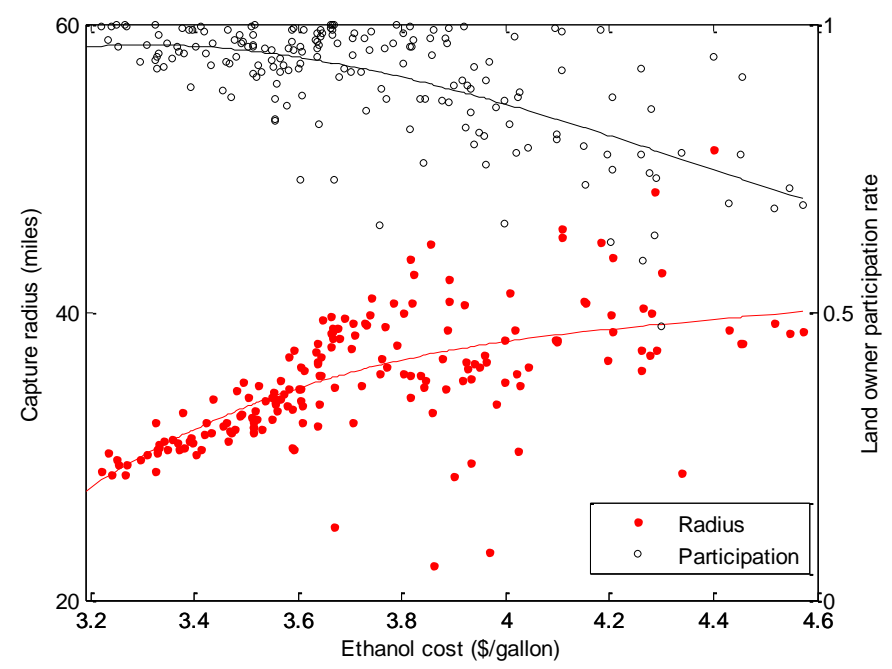

\subsection{Comparison to cost model without procurement tradeoff}

Aggregating our district supply cost estimates provides a step-wise approximation to the switchgrass ethanol supply curve, referred to as the "baseline" in Figure 4. If each district in the dataset builds a least-cost plant, then total estimated production could reach 9.5 billion gallons per year (bgy) at a marginal cost of $\$ 4.57$ for the last gallon produced. In reality, the model is constrained by yields, land availability, opportunity cost, and districts included; it is probable that aggregate supply costs could be reduced by relaxing these constraints and expanding biofuel production in low-cost regions.

Figure 4 illustrates how the baseline supply estimate compares to supply curves derived from a model with a fixed biomass price and a fixed local participation rate. To evaluate these alternative modeling approaches, two scenarios are considered. In Scenario 1, the fixed participation rate and opportunity cost are based on the average rate of the 10 least-cost baseline plant locations; in other words, Scenario 1 extrapolates the best-case conditions to all districts. Scenario 2 uses the average participation rate and opportunity cost of all 182 baseline plant 
locations. For both scenarios, all other switchgrass production costs are unchanged from the baseline model.

Figure 4 - Estimated supply curve with and without procurement tradeoff

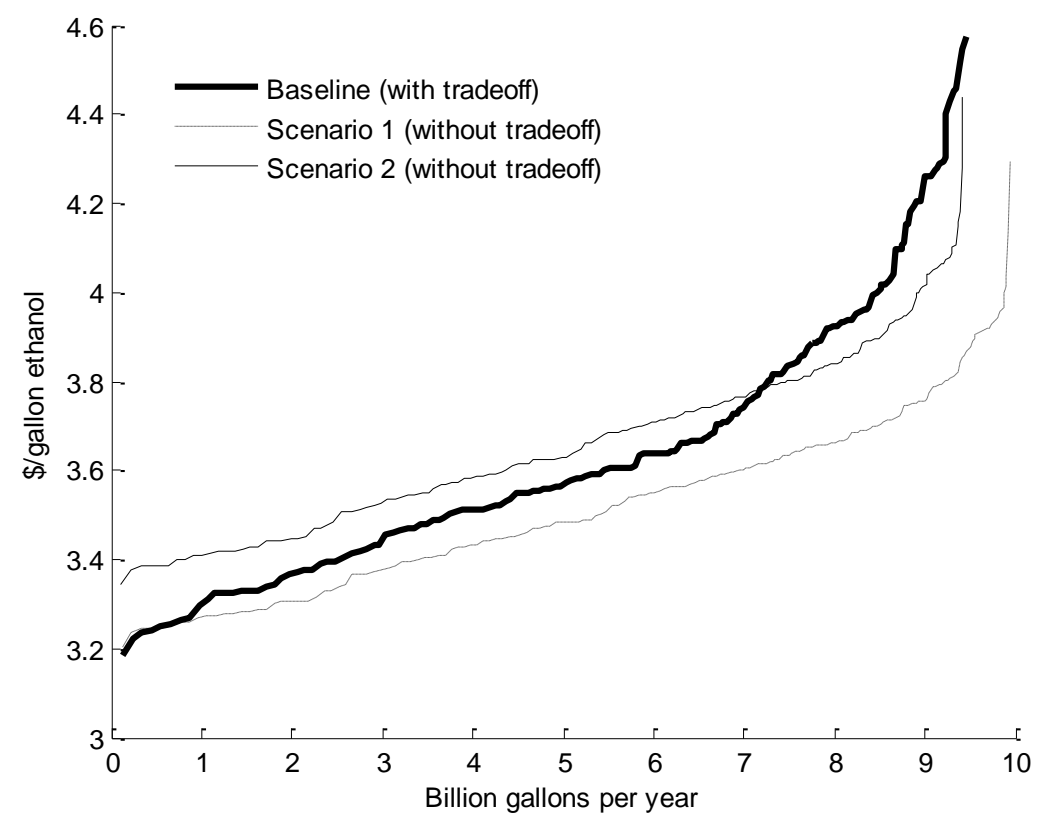

Relative to the baseline, Scenario 1 underestimates the average cost of ethanol production (beyond $1 \mathrm{bgy}$ ) and overestimates total supply. Scenario 2 overestimates the cost of ethanol production up to $7.5 \mathrm{bgy}$ and underestimates the cost of production beyond. The Scenario 2 supply curve crosses the baseline curve because this scenario assumes all 182 districts have the average participation rate and opportunity cost, which applies less weight to efficient plants and more weight to inefficient plants. Figure 4 illustrates the additional flexibility in the baseline supply curve when substitution in procurement between participation rate and capture radius is included in the cost model. The supply curves for Scenarios 1 and 2 are relatively flat up to 8.5 bgy because important substitution opportunities in biomass procurement are ignored. For biomass ethanol policy purposes, the baseline model better informs policymakers on the potential supply costs of expanding biofuel production. 
The counterfactual aggregate supply curves in Figure 4 abstract from the district-level impacts of a fixed biomass price and local participation rate. The extent to which biofuel costs and plant size are over- or underestimated depends on how close these fixed assumptions are to the actual district-level conditions. If the conditions identified with an endogenous participation rate (i.e., baseline model) differ markedly from the fixed price and participation assumptions, not only will the estimated cost and plant size differ but the relative attractiveness of plant locations (i.e., order of entry) will change. To illustrate, Figure 5 considers three districts in the same state and compares our supply estimates to those derived under Scenario 2 (i.e., assuming an average production environment for all locations). For district A, the fixed assumptions are close to the minimum point on district A's cost surface, and the estimated cost and plant size are similar in our model and Scenario 2. However, the fixed price and participation assumptions do not represent districts B and C as well, as can be seen in Figure 5. District B has high land opportunity costs and low switchgrass yields relative to the average production environment. The minimum of district B's cost surface occurs at significantly lower participation rate and higher opportunity cost than the fixed assumptions. As a result, the fixed model underestimates biofuel cost by almost $\$ 0.10$ per gallon. Conversely, district $\mathrm{C}$ has relatively low land opportunity costs and the fixed model over-estimates cost by $\$ 0.05$ per gallon. Based on cost per gallon, the fixed model would suggest location B before location C; more flexible model results reverse this order of entry into the aggregate supply curve.

Although the districts in Figure 5 are located in the same state, the degree to which cost estimates from Scenario 2 differ from the baseline varies. Moving beyond districts within the same state, the variation in supply effects increases as differences in switchgrass yields and 
Figure 5 - Sensitivity of district-level supplies to Scenario 2 assumptions for three districts in the same state

\section{$\underline{\text { District A }}$}

Endogenous Participation Rate

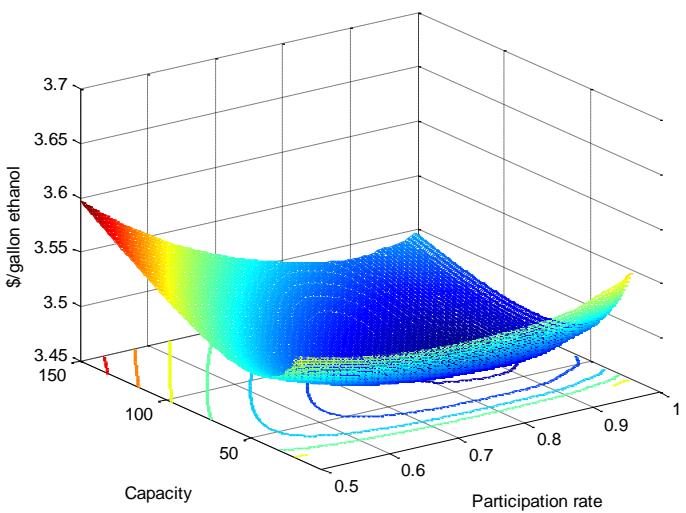

Fixed participation rate and opportunity cost

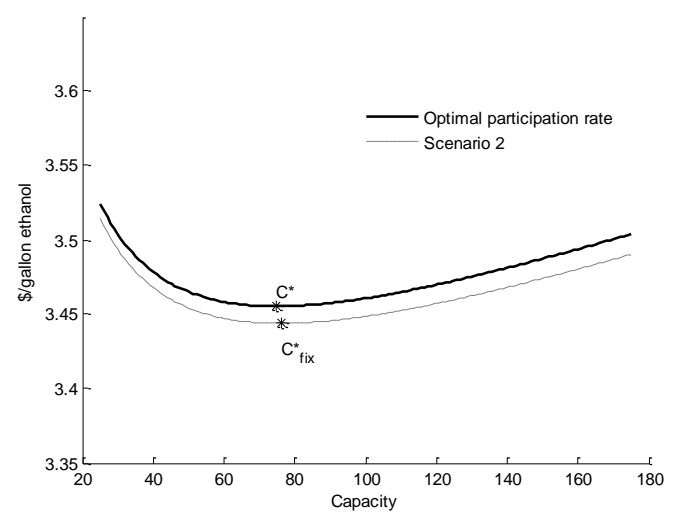

$\underline{\text { District B }}$

Endogenous Participation Rate

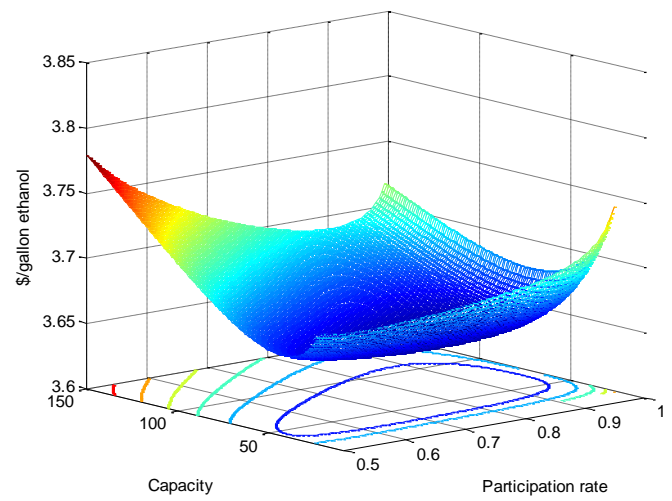

\section{$\underline{\text { District C }}$}

Endogenous Participation Rate

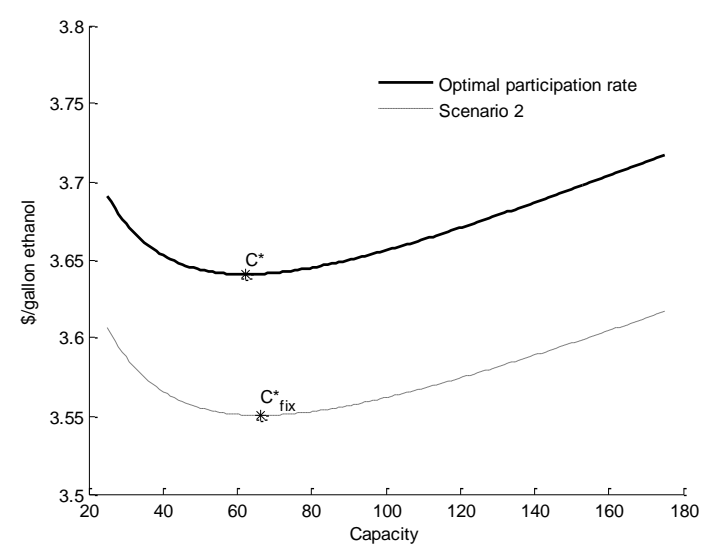

Fixed participation rate and opportunity cost

Fixed participation rate and opportunity cost

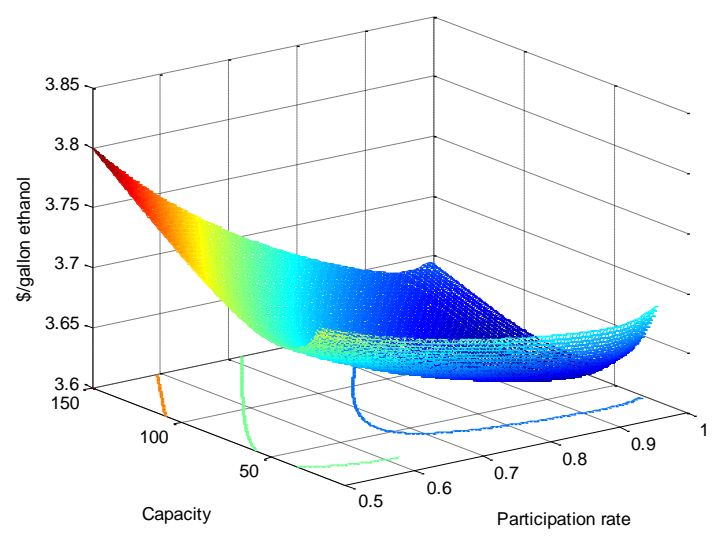

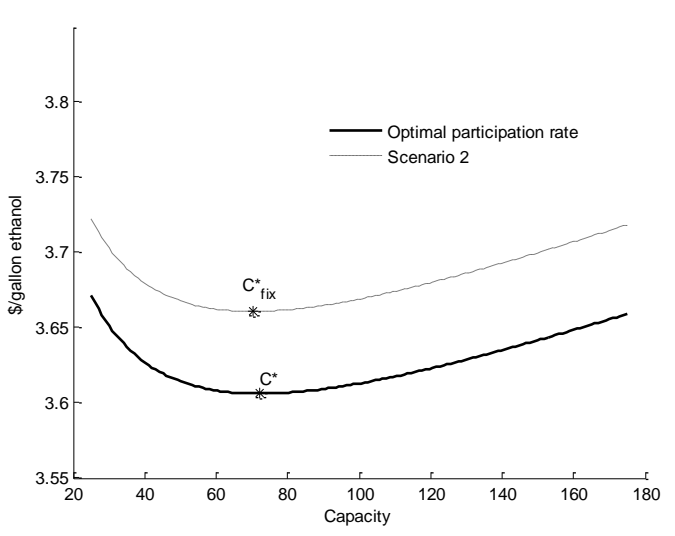


opportunity costs become more pronounced. As a result, the lower end of the supply curves in Figure 4 are fairly stable in terms of order of entry of plants. However, beyond 4 bgy, the estimated cost and order of entry of plants between the fixed and baseline models become markedly different for some districts. For example, across the 182 districts, the largest difference in the estimated per gallon cost is $\$ 0.63$ per gallon and largest repositioning of a plant in terms of its order of entry is 64 spots. Thus, even more important than the aggregate supply cost estimates, if policy incentives to spur the cellulosic biofuel industry are based on models with fixed price and participation rate assumptions, they may misdirect spatial efforts in promoting biofuel industry expansion.

\section{Conclusions}

A common approach in the literature that assesses biomass availability for biofuel is to assume the processor faces a fixed biomass participation rate by producers within the local production supply region. The use of a fixed participation rate provides a useful analytical simplification. But, as demonstrated, this simplification ignores important substitution opportunities in biomass procurement. A long-run cost model is presented that allows the producers' participation rate to vary with the price that the biofuel processor is willing to offer to procure biomass. Specifically, we model a biofuel processor that jointly chooses a plant size and the biomass price that minimizes feedstock procurement and processing costs while recognizing the procurement trade-off between the participation rate and capture radius.

An application of the model to switchgrass ethanol in 182 U.S. CRDs found that plant sizes and procurement conditions vary widely across districts. Accounting for the variation in landowners' opportunity costs has important implications on the processor's plant size and procurement decisions. In regions with higher switchgrass yields, lower land opportunity costs, 
and a greater percentage of potential cropland available for biomass production, larger plants can be built and biomass procured from more concentrated and lower cost production districts to a point. As biofuel production expands into regions with higher opportunity cost land, the processor builds smaller plants, targets a lower participation rate, and procures biomass from a relatively larger capture radius.

A comparison of our model results to models that use a fixed participation rate and biomass price illustrates the additional variation in the biofuel supply curve when accounting for this procurement tradeoff. The fixed model does not permit the flexibility that exists for the most efficient locations and assumes more flexibility than actually exists for higher cost locations. Identifying these potential cost tradeoffs are especially important for a fledgling industry.

The empirical application considered a single feedstock (switchgrass). If plants can use multiple feedstocks (e.g., switchgrass and corn stover), these estimates will serve as an upper bound on feedstock costs and biofuel costs, particularly in cash crop intensive CRDs that enter at higher costs. With the ability to convert multiple feedstocks, these plants may realize significant cost savings by procuring biomass more intensively near the plant. Finally, the empirical application herein only considered one source of biomass producer heterogeneity via differences in land opportunity costs. With additional data available, the proposed cost model can be extended to capture additional sources of heterogeneity such as biomass yields. In that case, the estimates presented here underestimate the potential impact of using a flexible model that captures the biomass procurement tradeoff. 


\section{Acknowledgements}

This project was supported in part by Iowa State University's Biobased Industry Center (BIC).

The content of this article, however, is the sole responsibility of the authors and does not necessarily reflect the views of the Biobased Industry Center. The authors gratefully acknowledge the USDA FSA and Economic and Policy Analysis Staff for access to Conservation Reserve Program data and Madhu Khanna and her colleagues for access to their switchgrass production cost and yield data.

\section{Bibliography}

Aden, A. "Biochemical Production of Ethanol from Corn Stover: 2007 State of Technology Model.” NREL: Technical Report. 2008. NREL/TP-510-43205.

. "State of Technology (SOT) Assessment." National Renewable Energy Laboratory, Analysis Platform Peer Review. March 20, 2009.

Aden, A., M. Ruth, K. Ibsen, J. Jechura, K. Neeves, J. Sheehan, B. Wallace, L. Montague, A. Slayton, and J. Lukas. "Lignocellulosic Biomass to Ethanol Process Design and Economics Utilizing Co-Current Dilute Acid Prehydrolysis and Enzymatic Hydrolysis for Corn Stover.” National Renewable Energy Laboratory. 2002. NREL/TP-510-32438.

Altman, I., J. Bergtold, D. Sanders, and Tom Johnson. "Willingness to Supply Biomass for Bioenergy Production: A Random Parameter Truncated Analysis." Energy Economics 47(2015): 1 - 10.

An, H., W. Wilhelm, and S. Searcy. "Biofuel and Petroleum-based Fuel Supply Chain Research: A Literature Review.” Biomass and Bioenergy 35(2011): 3763 - 3774.

Babcock, B., S. Marette, S., and D. Tréguer. “Opportunity for Profitable Investments in Cellulosic Biofuels.” Energy Policy 39(2011): 714-719.

Bergtold, J., J. Fewell, and J. Williams. "Farmers' Willingness to Produce Alternative Cellulosic Bifouel Feedstocks under Contract in Kansas using State Choice Experiments." BioEnergy Research 7(2014): 876-884.

Brechbill, S., and W. Tyner. "The Economics of Biomass Collection, Transportation, and Supply to Indiana Cellulosic and Electric Utility Facilities." Purdue University, Department of Agricultural Economics. 2008. Working Paper \#08-03. 
Brown, R. Biorenewable Resources: Engineering New Products from Agriculture. Ames, Iowa: Iowa State Press, 2003.

de La Torre Ugarte, D., M. Walsh, H. Shapouri, and S. Slidnsky. "The Economic Impacts of Bioenergy Crop Production on U.S. Agriculture.” 2003. Washington, DC: U.S. Department of Agriculture.

English, B, D. de La Torre Ugarte, C. Hellwinckel, K. Jensen, R. Menard, T. West, and C. Clark. "Implications of Energy and Carbon Policies for the Agriculture and Forestry Sectors." Department of Agricultural and Resource Economics, Institute of Agriculture, The University of Tennessee, 2010.

English, B., D. de La Torre Ugarte, K. Jensen, C. Hellwinckel, R. Menard, B. Wilson, R. Roberts, and M. Walsh. "25\% Renewable Energy for the United States by 2025: Agricultural and Economic Impacts.” The University of Tennessee, Department of Agricultural Economics, 2006.

Gan, J., and C. Smith. "Optimal Plant Size and Feedstock Supply Radius: A Modeling Approach to Minimize Bioenergy Production Costs.” Biomass and Bioenergy 35(2011): 1-10.

Haque, M., and F. Epplin. "Cost to Produce Switchgrass and Cost to Produce Ethanol from Switchgrass for Several Levels of Biorefinery Investment Cost and Biomass to Ethanol Conversion Rates.” Biomass and Bioenergy 46(2012): 517-530.

Kazi, F., J. Fortman, R. Anex, G. Kothandaraman, D. Hsu, A. Aden, and A. Dutta. "TechnoEconomic Analysis of Biochemical Scenarios for Production of Cellulosic Ethanol." National Renewable Energy Laboratory, 2010. NREL/TP-6A2-46588.

Khanna, M., X. Chen, H. Huang, and H. Onal. "Supply of Cellulosic Biofuel Feedstocks and Regional Production Patterns." American Journal of Agricultural Economics 93(2011): $1-8$.

Leboreiro, J., and A. Hilaly. "Biomass Transportation Model and Optimum Plant Size for the Production of Ethanol.” Bioresource Technology 102(2011): 2712-2723.

Menard, J., K. Jensen, J. Qualls, B. English, and C. Clark. "2009 Southeastern United States Switchgrass Production Survey: Summary of Results.” BEAG Report, 2011.

Miranowski, J., Khanna, K. and Hess, R. "Economics of Feedstock Production, Harvest, Storage, and Transport." Chapter 11 in Sustainable Feedstocks for Advanced Biofuels: Sustainable Alternative Fuel Feedstock Opportunities, Challenges and Roadmaps for Six U.S. Regions. Editors: R. Braun, D. Karlen, and D. Johnson. Proceedings of the Sustainable Feedstocks for Advance Biofuels Workshop. Atlanta, GA. September 28-30, 2010.

Parker, N., Q. Hart, P. Tittmann, and B. Jenkins. "National Biofuel Supply Analysis.” Report prepared for the Western Governor's Association. 2011. Contract 20113-03.

Popp, M., and R. Hogan Jr. "Assessment of Two Alternative Switchgrass Harvest and Transport Methods." Farm Foundation Conference Paper. St. Louis, Missouri, April 12-13, 2007. 
Qualls, D., K. Jensen, B. English, J. Larson, and C. Clark. "Analysis of Factors Affecting Farmers' Willingness to Adopt Switchgrass Production.” Selected paper prepared for presentation at the Southern Agricultural Economics Association Annual Meeting, Corpus Christi, TX, February 5-8, 2011.

Rosburg, A. "Cellulosic Biofuel Supply with Heterogeneous Biomass Suppliers: An Application to Switchgrass-based Ethanol." Chapter 4 in Essays Concerning the Cellulosic Biofuel Industry, Doctoral Dissertation 12725, Iowa State University, Department of Economics, 2012, http://lib.dr.iastate.edu/etd/12725.

Rosburg, A., and J. Miranowski. "An Economic Evaluation of US Biofuel Expansion Using the Biofuel Breakeven Program with GHG Accounting." AgBioForum 14(2011): 111-119.

Rosburg, A., J. Miranowksi, and K. Jacobs. "Cellulosic Biofuel Supply with Heterogeneous Biomass Suppliers: An Application to Switchgrass-based Ethanol.” Selected paper prepared for presentation at the 16th International Consortium on Applied Bioenergy Research (ICABR) Annual Conference, Rome, Italy, June 24-27, 2012.

Sesmero, J. and B. Gramig. "Farmers' Supply Response, Price of Corn Residue, and Its Economic Viability as an Energy Feedstock.” BioEnergy Research 6(2013): 797-807.

Sesmero, J, M. Pratt, and W. Tyner. "Supply Response, Marginal Cost, and Soil Erosion Implications of Stover-based Biofuels." Applied Economic Perspectives and Policy (2014).

Sharma, B., R. Ingalls, C. Jones, and A. Khanchi. "Biomass Supply Chain Design and Analysis: Basis, Overview, Modeling, Challenges, and Future." Renewable and Sustainable Energy Reviews 24(2013): 603 - 627.

U.S. Department of Energy (DOE). “U.S. Billion-Ton Update: Biomass Supply for a Bioenergy and Bioproducts Industry”. R.D. Perlack and B.J. Stokes (Leads). 2011. U.S. Department of Energy. Oak Ridge National Laboratory, Oak Ridge, TN. ORNL/TM-20011/224. $227 p$.

U.S. Environmental Protection Agency (EPA). "Renewable Fuel Standard (RFS)." March 26, 2012. Retrieved April 2, 2012, from http://www.epa.gov/otaq/fuels/renewablefuels/index.htm

Wright, L., and A. Turhollow. "Switchgrass Selection as a "Model” Bioenergy Crop: A History of the Process.” Biomass and Bioenergy 34(2010): 851-868.

Yu, T.E., Z. Wang, B. English, and J. Larson. "Designing a Dedicated Energy Crop Supply System in Tennessee: A Multiobjective Optimization Analysis." Journal of Agricultural and Applied Economics 46(2014): 357 - 373. 